\title{
Low uptake of continuous subcutaneous insulin infusion therapy in people with type 1 diabetes in Ireland: a retrospective cross- sectional study
}

\author{
Katarzyna Anna Gajewska ${ }^{1 *}$ (D, Kathleen Bennett', Regien Biesma² and Seamus Sreenan ${ }^{3,4}$
}

\begin{abstract}
Background: The uptake of continuous subcutaneous insulin infusion (CSII) therapy in those with type 1 diabetes varies internationally and is mainly determined by the national healthcare reimbursement systems. The aim of this study is to estimate national and regional uptake of CSII therapy in children, adolescents and adults with type 1 diabetes in Ireland.

Methods: A retrospective cross-sectional study was conducted utilizing the national pharmacy claims database in 2016. Individuals using CSII were identified by dispensing of infusion sets. The uptake of CSII was calculated as the percentage of people with type 1 diabetes claiming CSII sets in 2016, both in children and adolescent (age $<18$ years) and adult populations ( $\geq 18$ years). Descriptive statistics including percentages with $95 \%$ confidence intervals (Cls) are presented, stratified by age-groups and geographical regions, and chi-square tests used for comparisons.

Results: Of 20,081 people with type 1 diabetes, 2111 (10.5, 95\% Cl: 10.1-10.9\%) were using CSII in 2016. Uptake was five-fold higher in children and adolescents at 34.7\% (95\% Cl: 32.9-36.5\%) than in adults at 6.8\% (95\% Cl: 6.4-7.2\%). Significant geographical heterogeneity in CSII uptake was found, from 12.6 to $53.7 \%$ in children and adolescents $(p<0.001)$, and 2 to $9.6 \%$ in adults $(p<0.001)$.
\end{abstract}

Conclusions: Uptake of CSII in people with type 1 diabetes is low in Ireland, particularly in those $\geq 18$ years. Identification of barriers to uptake, particularly in this group, is required.

Keywords: Diabetes mellitus, type 1, Insulin infusion systems, Insulin pump, Epidemiology, Health services research, Cross-sectional studies

\section{Background}

Continuous Subcutaneous Insulin Infusion (CSII) was introduced as a mode of insulin administration for type 1 diabetes in the late 1970s [1]. The International Society of Paediatric and Adolescent Diabetes (ISPAD) recommends CSII as a preferred method of insulin

\footnotetext{
* Correspondence: katarzynagajewska@rcsi.ie

'Division of Population Health Scineces, RCSI: University of Medicine and Health Sciences, Dublin, Ireland

Full list of author information is available at the end of the article
}

administration for preschool children [2], due to its advantages: better precision and accuracy; flexibility; ease of insulin delivery [1]. Consensus statements from the major international diabetes associations [3] and systematic reviews and meta-analyses [4] suggest a lower risk of hypoglycaemia (including severe events), as well as modest reductions in glycated haemoglobin $\left(\mathrm{HbA}_{1 \mathrm{c}}\right)$ when comparing CSII to insulin injections in those under 18 years of age $[3,4]$.

C C The Author(s). 2020 Open Access This article is licensed under a Creative Commons Attribution 4.0 International License, which permits use, sharing, adaptation, distribution and reproduction in any medium or format, as long as you give appropriate credit to the original author(s) and the source, provide a link to the Creative Commons licence, and indicate if changes were made. The images or other third party material in this article are included in the article's Creative Commons licence, unless indicated otherwise in a credit line to the material. If material is not included in the article's Creative Commons licence and your intended use is not permitted by statutory regulation or exceeds the permitted use, you will need to obtain permission directly from the copyright holder. To view a copy of this licence, visit http://creativecommons.org/licenses/by/4.0/ The Creative Commons Public Domain Dedication waiver (http://creativecommons.org/publicdomain/zero/1.0/) applies to the data made available in this article, unless otherwise stated in a credit line to the data. 
The effectiveness of CSII in adult populations with type 1 diabetes is less evident: systematic reviews and randomized controlled trials (RCTs) of CSII effectiveness in adults with type 1 diabetes reported advantages over multiple daily injections (MDI) such as better control of glucose levels, less hypoglycaemia and quality of life gains [5-7]. Some studies, however, fail to show significant clinical benefit of CSII over MDI, when both randomized groups received the same structured education program [8]. CSII is more complex, requires provision of additional training and education [9], and is a more expensive mode of therapy. A longitudinal analysis of the Swedish National Diabetes Register found the average costs were approximately $\$ 4000$ more per annum compared to MDI only [10]. However, some studies have suggested that CSII is associated with reduced risk of diabetes-related complications [11, 12], including lower cardiovascular mortality [13].

Notwithstanding the benefits, there is still limited uptake of CSII in those with type 1 diabetes, although there have been increases, mainly in well-developed countries, in those where CSII is reimbursed, and in younger aged populations [1, 14]. From what is already known, the uptake of CSII is usually lower in adults than in children with type 1 diabetes (e.g. in Scotland [15] or Italy [16]), due, in part, to factors such as the health system structure and different reimbursement strategies for children and adolescents compared to adults. In Germany and Austria, the percentage of people using CSII increased from $1 \%$ in 1995 to $53 \%$ in 2017 across all ages, with the highest uptake in the youngest age group $(92 \%$ of German and Austrian pre-schoolers) [14]. Comparison between three large paediatric diabetes registries in 2015 showed that $47 \%$ of children in the United States (US T1D Exchange), $41 \%$ in Germany and Austria (DPV), and $14 \%$ in the English/Welsh National Pediatric Diabetes Audit [17] were using CSII. Evidence from 2017 using data from large diabetes registries found the level of uptake of CSII in adults varied from 9.4\% in Scotland [15] to $37 \%$ in Germany [14]. As CSII is fully reimbursed in Ireland, as in most of the countries mentioned above (excluding the US), in this study we aimed to estimate the national and regional uptake of CSII in children, adolescents and adults with type 1 diabetes in Ireland.

\section{Methods}

A retrospective cross-sectional study was conducted utilizing the Irish Health Service Executive Primary Care Reimbursement Service (HSE-PCRS) national pharmacy claims database for 2011-2016. The STrengthening the Reporting of OBservational Studies in Epidemiology (STROBE) statement checklist was followed to ensure the quality of conduct and reporting of the study.

\section{Settings / data sources}

The HSE-PCRS pharmacy claims database records (anonymously) monthly dispensed medications from the government funded medication reimbursement schemes in Ireland: Drug Payment (DP), General Medical Services (GMS), and Long-Term Illness (LTI) schemes [18]. People with diabetes have their treatment-related costs fully covered by the state (including insulin, glucometer test strips, insulin pump infusion sets, etc.) mainly through the LTI scheme [19]. LTI and GMS schemes are available to all Irish citizens with diabetes, irrespective of whether their care is provided through the public or private system or in primary or secondary care. The database records basic demographic information, including gender, age group and locality of residence, and the type of medication for diabetes, according to the World Health Organization (WHO) Anatomical Therapeutic Classification (ATC) codes for diabetes (A10) [20]. More detailed information about the HSE-PCRS database can be found elsewhere [18]. Ethical approval to conduct the study was not required as the data were anonymised and permission was provided from the data controllers (HSE-PCRS) for use of the data for this specific study.

\section{Study population and definitions}

The study population included people with type 1 diabetes living and claiming their diabetes-related prescriptions, including CSII sets, in Ireland in 2016. The final population of those with type 1 diabetes $(20,081)$ was estimated as part of another study using similar methodology and the HSE-PCRS data-set. The criteria and definition of a person with type 1 diabetes were complex and included: continuous use of insulin (any type) and glucose test strips (any type); those who used oral hypoglycaemic agents for the 12 months prior to commencing insulin, and those on long-acting insulin only, were excluded from analysis. More details about the methodology, its strengths and limitations, the criteria and definitions are fully described elsewhere [19].

\section{Statistical analysis}

The uptake of CSII was calculated as the percentage of people with type 1 diabetes claiming CSII sets in 2016. Descriptive statistics, including percentages with 95\% confidence intervals (CIs), are presented. Type 1 diabetes is most often described in the paediatric population, and there are fundamental differences in the approach, treatments, needs, problems and delivery of diabetes care between children and adults with type 1 diabetes [21]. Thus we decided to stratify the data for the paediatric population (children and adolescents aged under 18 years), and adults (aged 18 and over) separately. In addition, in a previous study on the prevalence of type 1 diabetes in Ireland the same stratification by paediatric 
and adult cases was used, as well as the stratification by age-groups used by the Irish Central Statistics Office [22] (0-14, 15-24, 25-34, 35-44, 45-54, 55-64, 65-74, $75+$ ) that allowed the prevalence rates for the Irish population to be estimated [19].

For the purposes of this study, analysis was conducted in 18 geographical areas related to 32 Local Health Offices areas [23] (Additional file 1 Table S1). Chi-square tests (including linear test for trend for age) were used to compare uptake of CSII across age groups and geographical regions. Significance at $p<0.05$ was assumed. The uptake by geographical regions of residence was mapped using ArcGIS software version 10.2.2. SAS statistical software version 9.4 and Microsoft Excel for Mac 2011 were used for analysis.

\section{Results}

There were 2111 people with diabetes claiming CSII sets in 2016, providing an overall uptake of CSII of 10.5\% (95\% CI: 10.1 to $10.9 \%$; Table 1 ). The uptake was fivefold higher in those aged < 18 years $(34.7,95 \% \mathrm{CI}: 32.9$ to $36.5 \%)$ than in those aged $\geq 18$ years $(6.8,95 \% \mathrm{CI}$ : 6.4-7.2\%). No information was available on age for $n=50$ (2\%). Of all those using CSII in Ireland, $43 \%$ were children and adolescents.

The uptake of CSII varied significantly between different age groups (Table 1) and geographical regions (Fig. 1, Table 2). There was a significant linear association of decreasing CSII use with increasing age $\left(\chi^{2}=\right.$ $1678.7, p<0.001)$. The highest uptake was in the youngest population (38\% in children aged $\leq 14$ years), through to 2.1 and $0.8 \%$ in the oldest age groups (people aged $65-74$ and over 75 years respectively; Table 1 ).

Significant variation in the overall uptake of CSII between regions was observed from 4\% (Co. Roscommon) to $15.8 \%$ in Co. Meath $\left(\chi^{2}=213.6, p<0.001\right.$; Table 2). High uptake was observed in areas close to the capital city - Dublin (12.6\% in Dublin and its suburbs), in counties Kildare \& Wicklow (15\%) and Carlow \& Kilkenny (12.9\%). There were differences in regional uptake between the paediatric and adult populations. In the paediatric population the uptake varied significantly $\left(\chi^{2}=105.2, p<0.001\right.$; Fig. 1, Table 2) and was lowest in county Mayo (12.6\%), and highest in county Meath (53.7\%). The region with the lowest uptake in the paediatric population was still higher than any uptake levels in adults. In adults the uptake varied from $2 \%$ (county Roscommon) to $9.6 \%$ (counties Kildare and Wicklow) and the differences were significant $\left(\chi^{2}=187.8\right.$, $p<0.001$; Fig. 1, Table 2). See Table 2 for more detailed regional information.

\section{Discussion}

This study found that $10.5 \%$ of those with type 1 diabetes were using CSII in Ireland in 2016. Overall, the uptake of CSII in children and adolescents was five-fold higher than in adults. The uptake was the highest, at $38 \%$, in the youngest age-group (0-14 years) and was significantly lower with increasing age. There was significant geographical heterogeneity in CSII uptake with a four-fold variation in uptake across regions for children and adolescents, and five-fold for adults.

In comparison to other countries where CSII therapy is fully reimbursed (all Western European countries), the uptake in Ireland is relatively low. The average uptake in Nordic, Central and Western countries was $15-20 \%$ in 2010 [24]. The uptake in Ireland is even lower than in other developed countries with no public funding, where CSII is available mainly to those with private health insurance. In 2014, 12\% of the population in Australia

Table 1 Uptake (n and \%) of Continuous Subcutaneous Insulin Infusion (CSII) therapy in people with type 1 diabetes in Ireland in 2016

\begin{tabular}{|c|c|c|c|c|}
\hline Age Group (Years) & CSII therapy users (Total numbers) & People with type 1 diabetes (total numbers) & \% Uptake of CSII & $95 \% \mathrm{Cl}$ \\
\hline $0-14$ & 702 & 1846 & $38.0 \%$ & 35.8 to $40.2 \%$ \\
\hline $15-24$ & 417 & 2182 & $19.1 \%$ & 17.5 to $20.8 \%$ \\
\hline $25-34$ & 239 & 2363 & $10.1 \%$ & 8.9 to $11.3 \%$ \\
\hline $35-44$ & 277 & 2831 & $9.8 \%$ & 8.7 to $10.9 \%$ \\
\hline $45-54$ & 235 & 2897 & $8.1 \%$ & 7.1 to $9.1 \%$ \\
\hline $55-64$ & 121 & 2889 & $4.2 \%$ & 3.5 to $4.9 \%$ \\
\hline $65-74$ & 55 & 2688 & $2.1 \%$ & 1.5 to $2.6 \%$ \\
\hline $75+$ & 15 & 1948 & $0.8 \%$ & 0.4 to $1.2 \%$ \\
\hline TOTAL & $2111^{a}$ & $20,081^{b}$ & $10.5 \%$ & 10.1 to $10.9 \%$ \\
\hline$<18$ years & 899 & 2591 & $34.7 \%$ & 32.9 to $36.5 \%$ \\
\hline$\geq 18$ years & 1162 & 17,053 & $6.8 \%$ & 6.4 to $7.2 \%$ \\
\hline
\end{tabular}

${ }^{a}$ There were 50 missing data for age (2\%) in the uptake of insulin pumps

${ }^{\mathrm{b}}$ There were 437 missing data for age $(2 \%)$ in the prevalence of type 1 diabetes 


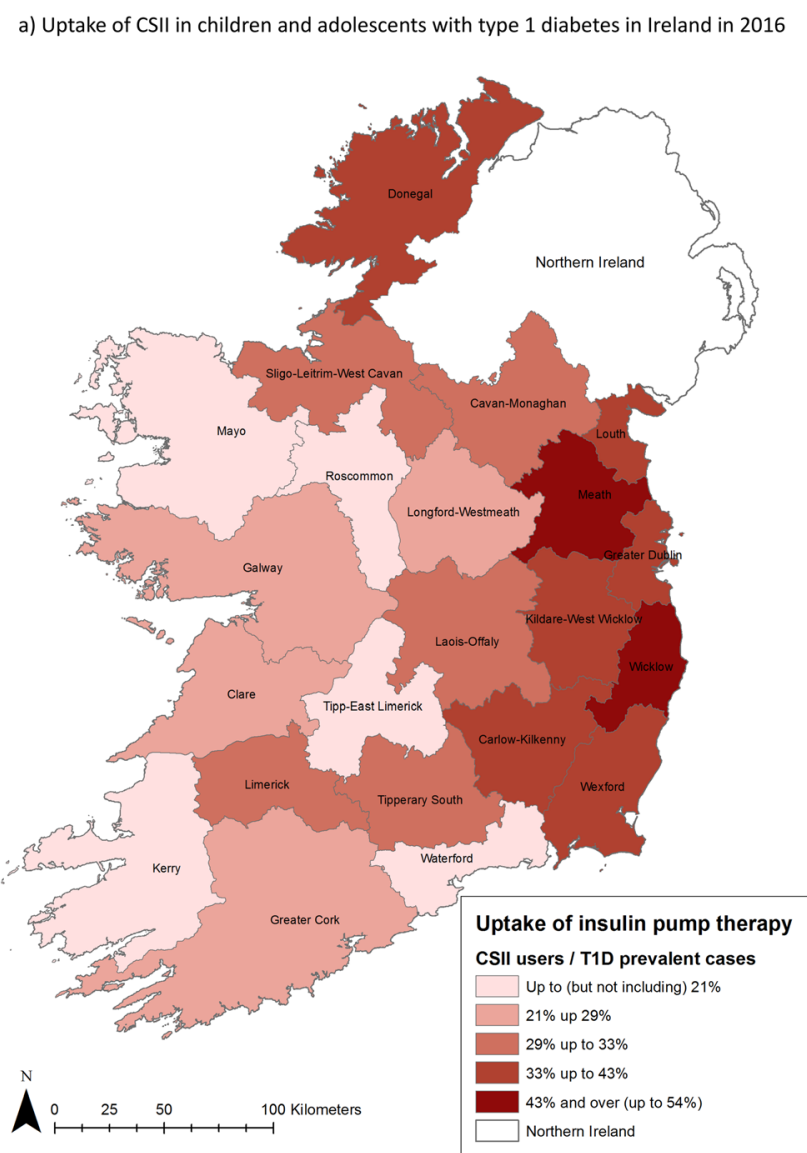

b) Uptake of CSII in adults with type 1 diabetes in Ireland in 2016

Source: The Irish Health Service Executive Primary Care Reimbursement Service

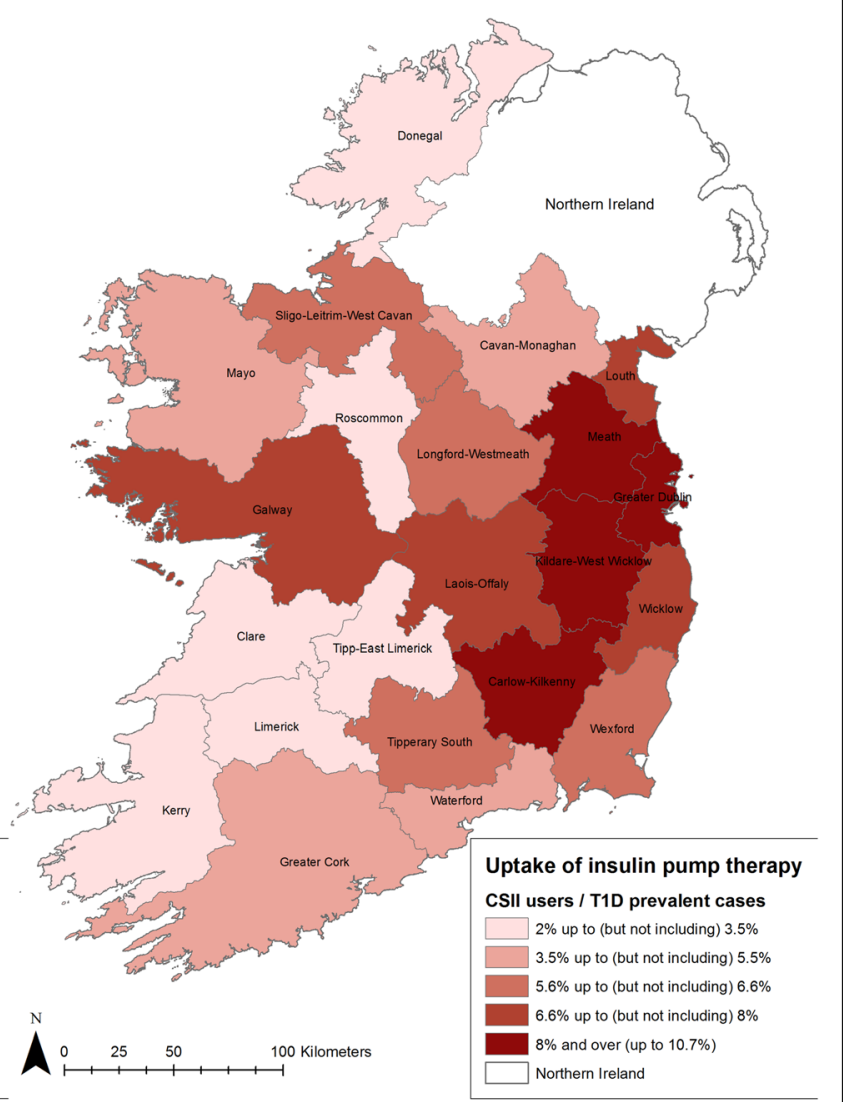

Fig. 1 The maps of the uptake of Continuous Subcutaneous Insulin Infusion in children and adolescents and adults with type 1 diabetes in Ireland in 2016. Copyright: Katarzyna Anna Gajewska

[25], and 59\% of those with type 1 diabetes participating in the T1D Exchange clinic registry in the US [26] were using CSII. However, the T1D Exchange registry includes 16,061 participants from 76 diabetes US clinics (38 adult and 38 paediatrics), so this figure may not represent that national picture as a whole.

The uptake of CSII in children and adolescents in Ireland $(34.7 \%)$ is similar to that in the UK where it was reported as $35.7 \%$ in those aged $<18$ years in England and Wales in 2019 [27] and in the 2017 Scottish National Survey [15]. However, the uptake of CSII in these countries is generally lower than in other Western countries. The highest uptake of CSII in children and adolescents was observed in Slovenia (74\%), with Sweden and Denmark also having $>50 \%$ uptake [28]. The study conducted within the SWEET network for paediatric diabetes centres (based on clinic databases from $>30$ paediatric clinics) suggests an average of $44 \%$ uptake across Europe (2016) [28], and 60\% of children and adolescents included in the US T1D Exchange clinic registry (38 clinics, 8483 participants aged < 18 years), [26] were using CSII in 2014.
In adults, the uptake of CSII in Ireland is also lower than in other countries where this mode of treatment is reimbursed [24]. Uptake has been reported to vary from $9.4 \%$ in Scotland [15], to 15\% in England [29] and Italy [16] (data from 2017), 21\% in Denmark (in one region) [30], 22\% in Sweden (data from 2015) [10], 24\% in Germany, Austria, Switzerland and Luxemburg (data from 2017) [31]. More recent data suggest that uptake of CSII in dutls from Germany only is $37 \%$ in 2017. [14]. Data from the US suggests that the uptake of CSII was even higher (59\%) in adults in 2014 [26], but for reasons outlined above, unlike the German data, the US figure may not be representative of the population as a whole $[14,26]$. Uptake of CSII in Irish adults is similar to Wales (6.7\%) [29], and to findings of the national audit of CSII care in the UK conducted in 2012 [9]. The authors of the UK report concluded that this prevalence was "well below the expectations of the National Institute for Health and Clinical Excellence (NICE) guidelines (15-20\%) or the European average (15\%)" and, therefore, steps have been undertaken in the UK, in particular in England, to improve the uptake $[15,29,32]$. As a result, uptake in adults 
Table 2 Geographical differences in the uptake of continuous subcutaneous insulin infusion in a whole population, children and adolescents, and adults over 18 with type 1 diabetes in Ireland in 2016

\begin{tabular}{llll}
\hline Geographical area & Uptake of CSII - All (\%); (95\% Cl) & Uptake (\%) of CSII in children and adolescents & Uptake (\%) of CSII in adults \\
\hline Carlow Kilkenny & $12.89 \%(10.30-15.44 \%)$ & $39.36 \%(29.49-49.24 \%)$ & $8.64 \%(6.33-10.95 \%)$ \\
Clare & $4.93 \%(2.82-7.03 \%)$ & $24.32 \%(10.50-38.15 \%)$ & $3.01 \%(1.26-4.77 \%)$ \\
Cork Combined & $7.60 \%(6.53-8.67 \%)$ & $31.64 \%(26.14-37.13 \%)$ & $4.43 \%(3.55-5.32 \%)$ \\
Donegal & $9.59 \%(7.66-11.51 \%)$ & $42.86 \%(34.66-51.05 \%)$ & $3.49 \%(2.17-4.81 \%)$ \\
Dublin Combined & $12.59 \%(11.72-14.36 \%)$ & $38.68 \%(34.80-42.56 \%)$ & $9.21 \%(8.39-10.03 \%)$ \\
Galway & $10.69 \%(8.70-12.68 \%)$ & $28.70 \%(20.43-36.96 \%)$ & $7.95 \%(6.08-9.82 \%)$ \\
Kerry & $4.31 \%(2.75-5.88 \%)$ & $20.29 \%(10.80-29.78 \%)$ & $2.43 \%(1.17-3.69 \%)$ \\
Kildare and Wicklow & $15.03 \%(13.28-16.78 \%)$ & $44.00 \%(37.85-50.15 \%)$ & $9.63 \%(8.03-11.24 \%)$ \\
Laois and Offaly & $10.72 \%(8.29-13.15 \%)$ & $30.53 \%(21.27-39.79 \%)$ & $7.03 \%(4.85-9.22 \%)$ \\
Limerick and Tipperary & $7.75 \%(6.38-9.12 \%)$ & $29.25 \%(23.12-35.37 \%)$ & $4.03 \%(2.93-5.14 \%)$ \\
Longford Westmeath & $9.67 \%(7.12-12.22 \%)$ & $27.50 \%(17.72-37.28 \%)$ & $6.56 \%(4.21-8.91 \%)$ \\
Louth & $11.77 \%(9.33-14.21 \%)$ & $38.78 \%(29.13-48.42 \%)$ & $7.09 \%(4.97-9.21 \%)$ \\
Mayo & $6.86 \%(4.70-9.02 \%)$ & $12.64 \%(5.66-19.63 \%)$ & $5.50 \%(3.36-7.65 \%)$ \\
Meath & $15.76 \%(13.21-18.30 \%)$ & $53.66 \%(44.85-62.47 \%)$ & $8.79 \%(6.63-10.95 \%)$ \\
Roscommon & $4.00 \%(1.44-6.56 \%)$ & $18.52 \%(3.87-33.17 \%)$ & $2.03 \%(0.06-4.00 \%)$ \\
Sligo, Leitrim, Cavan, Monaghan & $8.55 \%(6.80-10.30 \%)$ & $30.58 \%(22.37-39.79 \%)$ & $5.32 \%(3.81-6.83 \%)$ \\
Waterford City and County & $8.15 \%(5.73-10.57 \%)$ & $20.45 \%(12.03-28.88 \%)$ & $5.33 \%(3.11-7.55 \%)$ \\
Wexford & $9.55 \%(7.42-11.68 \%)$ & $36.00 \%(25.14-46.86 \%)$ & $6.31 \%(4.42-8.20 \%)$ \\
ALL IRELAND & $\mathbf{1 0 . 5 1 \% ( 1 0 . 0 9 - 1 0 . 9 4 \% )}$ & $\mathbf{3 4 . 7 0 \% ( 3 2 . 8 6 - 3 6 . 5 3 \% )}$ & $\mathbf{6 . 8 1 \% ( 6 . 4 4 - 7 . 1 9 \% )}$ \\
\hline
\end{tabular}

in England and Scotland has doubled since 2012 [15, 29], but this is still below that in the Nordic countries, Germany or the US [10, 26, 30, 31]. In Ireland, there are no standardized criteria or clinical recommendations for the use of CSII therapy in adults at present [33], which may be one of the factors for the low uptake of CSII. Commencement of CSII is usually at the discretion of the physician and team looking after the person with diabetes although aiming to optimize control, limit hypoglycaemia, improve hypoglycaemia awareness and personal preferences would be common indications. Having more firm guidelines could direct physicians to recommend CSII more often. On the other hand, bearing in mind lower uptake in the UK when comparing to Nordic countries, strict criteria, as those in the NICE guidelines, may have an impact on the poor uptake of CSII also. It is worth to note, that many health-care professionals in Ireland receive their postgraduate training (as well as training to provide CSII services) in the UK, therefore the NICE criteria are well-known by significant percentage of specialists in diabetes in Ireland. Other possible barriers to uptake, in particular in adults, might be similar to those explored by Italian researchers. According to the Third Italian Survey of CSII, high costs of CSII and lack of multidisciplinary teams (MDT) are perceived as limiting factors for CSII uptake [34]. The availability of CSII was explored more in-depth in a national survey of CSII services provision in adult clinics in Ireland. The scarcity of trained staff, as shown in the survey findings, means that full MDTs were not always available (e.g. lack of dietetic support), and the lack of MDT and perceived work overload were listed as barriers to CSII provision [35]. Another barrier might be related to people with diabetes lack of willingness to be attached to a device and a burden associated with technology use [36, 37].

The diversity in uptake of CSII between different age groups is common. Authors of the study conducted in Sweden concluded that people aged between 20 and 30 years were more than twice as likely to initiate use of CSII than those aged 40-50 years [38], and data from registries suggest that younger people with type 1 diabetes use CSII more often than older adults [15, 29]. CSII is recommended by ISPAD as a preferred mode of treatment in the youngest population [1]. CSII is often initiated in pre-school children due to their and their families' needs related to unpredictable food patterns, low insulin requirements, reduction in the number of injections, ease of insulin delivery and needle-phobia [1], which helps explain why CSII is used more by younger people [29]. These needs have been recognized by the Irish National Paediatric Clinical Programme which introduced a model of care for the provision of CSII in children aged $\leq 5$ years in 2012 [39]. This policy 
document recommends offering CSII to every child with type 1 diabetes under the age of 5 years, which may have contributed to the large difference in uptake between paediatric and adult populations.

Evidence on geographical variation in CSII uptake [15, $27,29,40]$ is lacking. Where evidence is available, for example, in Scotland, the variation was found to be two-fold from 27.1 to $60 \%$ in the paediatric population and 6.7 to $15.2 \%$ in adults [15] in 2017. This variation was not as high as that found in our study. There were four-fold differences between the overall uptake in Ireland and in children in adolescents, while a five-fold difference was observed in adults. Overall, the areas of high uptake seem to be centralized around Dublin both in the paediatric and adult populations. Low uptake seems to be more often in rural areas, such as Roscommon, Clare or Kerry. The rural-urban difference might partly explain such a heterogeneity, although there are exceptions such as Donegal which has one of the highest uptakes of CSII in children and adolescents despite being considered "rural". Another explanation might be related to the age distribution of local populations. The youngest populations are in parts of Dublin and adjacent counties, whereas the oldest are in rural counties [41]. However some areas with older populations also have higher uptake than areas where the population is younger. This suggests that determinants are more complex than age, and rural-urban disparities. Previous data from Italy also shows geographical disparity even though the Italian health system covers the cost of devices; geographical disparity was explained by different regional regulations in terms of prescription rules and requirements [34]. In Ireland, prescription regulations are the same, but diversity in uptake could be affected by local health offices where decisions regarding funding are made [42].

This study aimed to estimate the uptake of CSII in Ireland and concludes that it is low both in the paediatric and adult populations. The reasons for such low uptake are not related to reimbursement since CSII is fully reimbursed in Ireland. The reasons are more complex, and may include lack of national standardized documents including guidelines for commencing CSII, the perceived excessive workload and the lack of resources $[16,34]$ This, however, has to be explored further with a use of more complex research methods.

The main strength of this study is that it is populationbased, nationwide and based on objective data. Our regional findings relate to the residence of those with diabetes and not where they receive their diabetes care; thus the findings accurately describe local access to CSII. This is the first study describing the uptake of CSII in all regions and the entire population of people with type 1 diabetes in Ireland. Data based on prescriptions claimed for CSII sets are a reliable and accurate source of information regarding CSII utilization.
This study has some limitations. It was not possible to monitor discontinuation of CSII, where others have shown discontinuation rates in the range 1-4\% [43]. Although the numbers using CSII reported are accurate, the uptake rates may be impacted on by the definition of type 1 diabetes cases, which was based on diabetes-specific prescriptions included in the pharmacy claims database. As information on the diagnosis (i.e. ICD-10 codes) is not available in the HSE-PCRS database and there is no diabetes registry in Ireland, some cases of people with type 2 diabetes receiving basal-bolus therapy or CSII may have been misclassified as type 1 diabetes. In addition, as the HSE-PCRS database is mainly used for the administrative purpose and does not contain any other medical information, there was no possibility to monitor the outcomes of CSII use, i.e. in levels of glycated haemoglobin $\left(\mathrm{HbA}_{1 \mathrm{c}}\right)$. Moreover, because Continuous Glucose Monitoring (CGM) sensors are not included in the HSE-PCRS database (funding is covered from a different budget), we were unable to investigate the uptake of sensor-augmented insulin pump therapy use.

\section{Conclusions}

Uptake of CSII remains low in Ireland when compared to other countries where, like Ireland, CSII is fully reimbursed. The uptake is five-fold higher in children/adolescents than in adults. Our regional findings accurately describe local access to CSII and suggest this access is unequal. This study highlights the potential under-utilisation of CSII in Ireland and suggests that further studies exploring potential barriers, both from the health-care providers' and patients' perspectives, are warranted. An understanding of the reasons for the low uptake of CSII will have important implications for improving the quality of care for people living with type 1 diabetes in Ireland. These findings will help to inform health service users and policymakers, and can help to support health-service planners in making decisions on healthservice resource distribution. Also, our study suggests that in a country without a national diabetes register, routinely collected administrative pharmacy claims data can be utilized to estimate the uptake of CSII. Finally, this study adds to limited international evidence on the uptake of CSII therapy in those with type 1 diabetes.

\section{Supplementary information}

Supplementary information accompanies this paper at https://doi.org/10. 1186/s12902-020-00573-w.

Additional file 1: Table S1. The list of 18 geographical areas based on the matching between 32 HSE-PCRS Local Health Offices (LHOs) and 31 CSO County and City areas.

\section{Abbreviations}

ATC classification: Anatomical Therapeutic Chemical classification; CGM: Continuous Glucose Monitoring; Cl: Confidence intervals; 
CSII: Continuous Subcutaneous Insulin Infusion; CSO: Central Statistics Office; DP: Drug Payment Scheme; GMS: General Medical Scheme; HSE: Health Service Executive; HSE PCRS: Health Service Executive Primary Care Reimbursement Service; isCGM: intermittently scanned Continuous Glucose Monitoring; ISPAD: International Society for Pediatric and Adolescent Diabetes; LHO: Local Health Office; LTI: Long-Term Illness Scheme; MDI: Multiple Daily Injection; MDT: Multidisciplinary team; NICE: National Institute for Health and Care Excellence; PCRS: Primary Care Reimbursement Service; RCT: Randomized Controlled Trial; STROBE: Strengthening the reporting of observational studies in epidemiology; T1D Exchange: Type 1 Diabetes Exchange; UK: United Kingdom; US: United States; WHO: World Health Organization

\section{Acknowledgements}

We thank the Health Service Executive Primary Care Reimbursement Service for supply of the data on which this study was based. We thank Mrs. Hannah Grove and Dr. Ronan Foley (Department of Geography, National University of Ireland, Maynooth) for their support in data mapping.

\section{Authors' contributions}

All authors were responsible for drafting the article and revising it critically for important intellectual content. K.A.G. contributed to the design of the study; the collection, analysis, and interpretation of data; the writing of the report; and the decision to submit the article for publication. R.B. and S.S. contributed to the design of the study; the interpretation of data; and the writing of the report and the decision to submit the article; K.B. contributed to the design of the study; the collection of data; the analysis and interpretation of data; the writing of the report and the decision to submit the article. All authors approved the version to be published.

\section{Funding}

This research was funded by the Health Research Board SPHeRE/2013/1 as a part of the PhD programme and KG is a HRB SPHeRE Programme scholar. KB is funded by a Health Research Board Award (RL-15-1579). The sponsor of this study had no contribution in the design of the study and collection, analysis, and interpretation of data and in writing the manuscript.

\section{Availability of data and materials}

The pharmacy claims data are managed by the HSE Primary Care Reimbursement Services and may be obtained in de-identified format for specific research purposes only. They are not permitted to be reused after analysis is completed. The formal permission to access to HSE-PCRS data granted for a limited period of use (6 months). To request access to the HSEPCRS data please visit the https://www.hse.ie/eng/staff/pcrs/pcrs-publications/ and complete the Information Request form.

\section{Ethics approval and consent to participate}

Our study was based on secondary data analysis of a fully anonymous dataset, and under the Data Protection Act 1998 in place at the time of the study, ethical approval and consent to participate were not required. The permission to access and use the dataset was granted by the data controller (Health Services Executive Primary Care Reimbursement Services).

\section{Consent for publication}

Not applicable.

\section{Competing interests}

The authors declare that there is no duality of interest associated with this manuscript.

\section{Author details}

'Division of Population Health Scineces, RCSI: University of Medicine and Health Sciences, Dublin, Ireland. ${ }^{2}$ Department of Health Sciences, Global Health, Univeristy Medical Centre Groningen, Groningen, the Netherlands. ${ }^{3} 3 \mathrm{U}$ Diabetes, RCSI: University of Medicine and Health Scineces, Dublin, Ireland. ${ }^{4}$ Diabetes and Endocrinology. RCSI: University of Medicine and Health Sciences, Connolly Hospital, Dublin, Ireland.
Received: 19 December 2019 Accepted: 11 June 2020

Published online: 23 June 2020

\section{References}

1. Sherr JL, Tauschmann M, Battelino T, de Bock M, Forlenza G, Roman R, et al. ISPAD clinical practice consensus guidelines 2018: diabetes technologies. Pediatr Diabetes. 2018;19(Suppl 27):302-25. https://doi.org/10.1111/pedi. 12731.

2. Sundberg F, Barnard K, Cato A, de Beaufort C, DiMeglio LA, Dooley G, et al. ISPAD guidelines. Managing diabetes in preschool children. Pediatr Diabetes. 2017;18(7):499-517. https://doi.org/10.1111/pedi.12554.

3. Phillip M, Battelino T, Rodriguez H, Danne T, Kaufman F, European Society for Paediatric E, et al. Use of insulin pump therapy in the pediatric agegroup: consensus statement from the European Society for Paediatric Endocrinology, the Lawson Wilkins Pediatric Endocrine Society, and the International Society for Pediatric and Adolescent Diabetes, endorsed by the American Diabetes Association and the European Association for the Study of Diabetes. Diabetes Care. 2007;30(6):1653-62. https://doi.org/10. 2337/dc07-9922.

4. Qin Y, Yang LH, Huang XL, Chen XH, Yao H. Efficacy and safety of continuous subcutaneous insulin infusion vs. multiple daily injections on type 1 diabetes children: a meta-analysis of randomized control trials. J Clin Res Pediatr Endocrinol. 2018;10(4):316-23. https://doi.org/10.4274/jcrpe.0053.

5. Cummins E, Royle P, Snaith A, Greene A, Robertson L, Mclntyre L, et al. Clinical effectiveness and cost-effectiveness of continuous subcutaneous insulin infusion for diabetes: systematic review and economic evaluation. Health Technol Assess. 2010;14(11):1. https://doi.org/10.3310/hta14110.

6. Roze S, Smith-Palmer J, Valentine W, de Portu S, Norgaard K, Pickup JC. Cost-effectiveness of continuous subcutaneous insulin infusion versus multiple daily injections of insulin in Type1 diabetes: a systematic review. Diabet Med. 2015;32(11):1415-24. https://doi.org/10.1111/dme.12792.

7. Benkhadra K, Alahdab F, Tamhane SU, McCoy RG, Prokop L, Murad MH. Continuous subcutaneous insulin infusion versus multiple daily injections in individuals with type 1 diabetes: a systematic review and meta-analysis. Endocrine. 2017;55(1):77-84. https://doi.org/10.1007/s12020-016-1039-x.

8. Repose Study Group. Relative effectiveness of insulin pump treatment over multiple daily injections and structured education during flexible intensive insulin treatment for type 1 diabetes: cluster randomised trial (REPOSE). BMJ. 2017;356:j1285. https://doi.org/10.1136/bmj.j1 285.

9. White HD, Goenka N, Furlong NJ, Saunders S, Morrison G, Langridge P, et al. The U.K. service level audit of insulin pump therapy in adults. Diabet Med. 2014;31(4):412-8. https://doi.org/10.1111/dme.12325.

10. Toresson Grip E, Svensson AM, Miftaraj M, Eliasson B, Franzen S, Gudbjornsdottir S, et al. Real-world costs of continuous insulin pump therapy and multiple daily injections for type 1 diabetes: a populationbased and propensity-matched cohort from the Swedish National Diabetes Register. Diabetes Care. 2019;42(4):545-52. https://doi.org/10.2337/dc181850.

11. Lucien M, Yukiko K-O, Jerome P, Corinne F, Dominique L, Fracoise B, et al. Long-term effects of continuous subcutaneous insulin infusion on glucose control and microvascular complications in patients with type 1 diabetes. J Diabetes Sci Technol. 2017;11(5):924-9.

12. Rosenlund S, Hansen TW, Andersen S, Rossing P. Effect of 4 years subcutaneous insulin infusion treatment on albuminuria, kidney function and $\mathrm{HbA1C}$ compared with multiple daily injections: a longitudinal followup study. Diabet Med. 2015;32(11):1445-52. https://doi.org/10.1111/dme. 12950.

13. Steineck I, Cederholm J, Eliasson B, Rawshani A, Eeg-Olofsson K, Svensson AM, et al. Insulin pump therapy, multiple daily injections, and cardiovascular mortality in 18,168 people with type 1 diabetes: observational study. BMJ. 2015;350:h3234. https://doi.org/10.1136/bmj.h3234.

14. van den Boom L, Karges B, Auzanneau M, Rami-Merhar B, Lilienthal E, von Sengbusch $S$, et al. Temporal trends and contemporary use of insulin pump therapy and glucose monitoring among children, adolescents, and adults with type 1 diabetes between 1995 and 2017. Diabetes Care. 2019. https:// doi.org/10.2337/dc19-0345.

15. McKnight JA, Scottish Diabetes Data Group. Scottish Diabetes Survey 2017. 2017. [cited 2017 Cited Cited]. Available from: http://www. diabetesinscotland.org.uk/Publications/SDS\%202017.pdf.

16. Bonfanti R, Lepore G, Bozzetto L, Corsi A, Di Blasi V, Girelli A, et al. Survey on the use of insulin pumps in Italy: comparison between pediatric and adult 
age groups (IMITA study). Acta Diabetol. 2016;53(3):403-12. https://doi.org/ 10.1007/s00592-015-0810-4.

17. Sherr JL, Hermann JM, Campbell F, Foster NC, Hofer SE, Allgrove J, et al. Use of insulin pump therapy in children and adolescents with type1 diabetes and its impact on metabolic control: comparisonof results from three large, transatlantic paediatric registries. Diabetologia. 2016;59:87-91. https://doi. org/10.1007/s00125-015-3790-6).

18. Sinnott SJ, Bennett K, Cahir C. Pharmacoepidemiology resources in Irelandan introduction to pharmacy claims data. Eur J Clin Pharmacol. 2017. https://doi.org/10.1007/s00228-017-2310-7.

19. Gajewska KA, Biesma R, Sreenan S, Bennett K. Prevalence and incidence of type 1 diabetes in Ireland: a retrospective cross-sectional study using a national pharmacy claims data from 2016. BMJ Open. 2020;10(4):e032916. https://doi.org/10.1136/bmjopen-2019-032916.

20. Methodology WCCFDS. WHO. Collaborating Centre for Drug Statistics Methodology: Anatomical Therapeutic Chemical (ATC) classification Index. Oslo: The Norwegian Institute of Public Health; 2017. [Available from: http:// www.who.int/medicines/regulation/medicines-safety/about/collab-centresnorwegian/en/.

21. Peters A, Laffel L, American Diabetes Association Transitions Working G. Diabetes care for emerging adults: recommendations for transition from pediatric to adult diabetes care systems: a position statement of the American Diabetes Association, with representation by the American College of Osteopathic Family Physicians, the American Academy of Pediatrics, the American Association of Clinical Endocrinologists, the American Osteopathic Association, the Centers for Disease Control and Prevention, Children with Diabetes, The Endocrine Society, the International Society for Pediatric and Adolescent Diabetes, Juvenile Diabetes Research Foundation International, the National Diabetes Education Program, and the Pediatric Endocrine Society (formerly Lawson Wilkins Pediatric Endocrine Society). Diabetes Care. 2011;34(11):2477-85. https://doi.org/10.2337/dc111723

22. CSO CSO. Population 2011 to 2016 by Age Group, Detailed Marital Status, County and City and CensusYear in Ireland 2016 [Available from: http:// www.cso.ie/px/pxeirestat/Statire/SelectVarVal/Define.asp?maintable=EY006 \&PLanguage $=0$.

23. Murphy ME, Bennett K, Fahey T, Smith SM. Geographical variation in antidiabetic prescribing in Ireland in 2013 and 2014: a cross-sectional analysis. Fam Pract. 2017. https://doi.org/10.1093/fampra/cm×036.

24. Renard E. Insulin Pump Use in Europe. Diabetes Technol Ther. 2010;12(1): 29-32.

25. Diabetes Australia. Insulin Pump Therapy In Australia - the case for action. 2014. Contract No.: Submission 102. [cited 2014 Cited Cited]. Available from: https://www.diabetesaustralia.com.au/news/13542?type=articles.

26. Miller KM, Foster NC, Beck RW, Bergenstal RM, DuBose SN, DiMeglio LA, et al. Current State of Type 1 Diabetes Treatment in the U.S.: Updated Data From the T1D Exchange Clinic Registry. Diabetes Care. 2015:38:971-8. https://doi.org/10.2337/dc15-0078/-/DC1.

27. National Paediatric Diabetes Audit, Royal College of Paediatrics and Child Health. National Paediatric Diabetes Audit 2017/18. 2019. [cited 2019 Cited Cited]. Available from: https://www.rcpch.ac.uk/sites/default/files/2019-05/ NPDA-national-report-2017-18_v2-updated-2019-05-30_0.pdf.

28. Szypowska A, Schwandt A, Svensson J, Shalitin S, Cardona-Hernandez R, Forsander $\mathrm{G}$, et al. Insulin pump therapy in children with type 1 diabetes: analysis of data from the SWEET registry. Pediatr Diabetes. 2016;17(Suppl 23):38-45. https://doi.org/10.1111/pedi.12416.

29. Healthcare Quality Improvement Partnership. National Diabetes Insulin Pump Audit Report, Main Report, 2016-2017. Government Statistical Service; 2018. [cited 2018 Cited Cited]. EAvailable from: https://digital.nhs.uk/dataand-information/publications/statistical/national-diabetes-audit/insulinpump-report-2016-17.

30. Kampmann U, Madsen LR, Bjerg L, Witte DR, Hasselstrom K, Ostergard T, et al. Prevalence and geographical distribution of insulin pump therapy in the Central Denmark region and its association with metabolic parameters. Diabetes Res Clin Pract. 2018;141:148-55. https://doi.org/10.1016/j.diabres. 2018.04.042

31. van Mark G, Lanzinger S, Barion R, Degenhardt M, Badis S, Noll H, et al. Patient and disease characteristics of adult patients with type 1 diabetes in Germany: an analysis of the DPV and DIVE databases. Ther Adv Endocrinol Metab. 2019;10:2042018819830867. https://doi.org/10.1177/ 2042018819830867
32. Hammond PJ. Improving access to insulin pump therapy: the role of the insulin pump network. J Diabetes Nurs. 2013:17:175-9.

33. Department of Health. In: Do H, editor. Adult type 1 diabetes mellitus. (NCEC National Clinical Guideline No. 17). Ireland; 2018.

34. Bruttomesso D, Laviola L, Lepore G, Bonfanti R, Bozzetto L, Corsi A, et al. Continuous subcutaneous insulin infusion in Italy: third National Survey. Diabetes Technol Ther. 2015;17(2):96-104. https://doi.org/10.1089/dia.2014. 0242.

35. Gajewska KA, Biesma R, Bennett K, Sreenan S. Availability of and access to continuous subcutaneous insulin infusion therapy for adults with type 1 diabetes in Ireland. Acta Diabetol. 2020;(online first). https://doi.org/10.1007/ s00592-020-01497-6

36. Franciosi M, Maione A, Pomili B, Amoretti R, Busetto E, Capani F, et al. Correlates of quality of life in adults with type 1 diabetes treated with continuous subcutaneous insulin injection. Nutr Metab Cardiovasc Dis. 2010; 20(1):7-14. https://doi.org/10.1016/j.numecd.2009.02.012.

37. Tanenbaum ML, Hanes SJ, Miller KM, Naranjo D, Bensen R, Hood KK. Diabetes device use in adults with type 1 diabetes: barriers to uptake and potential intervention targets. Diabetes Care. 2017;40(2):181-7. https://doi. org/10.2337/dc16-1536.

38. Carlsson BM, Andersson PN, Alnervik J, Carstensen J, Lind M. Availability of insulin pump therapy in clinical practice. Diabet Med. 2012;29(8):1055-9. https://doi.org/10.1111/j.1464-5491.2011.03517.x.

39. O'Riordan S, Turner G, Group obotPDW. Model of Care for the Provision of Continuous Subcutaneous Insulin Infusion for the treatment of Type 1 Diabetes in the Under Five Age Group. Royal College of Physicians in Ireland Health Service Executive; 2012. [cited 2012 Cited Cited]. Available from: https://www.hse.ie/eng/services/publications/clinical-strategy-andprogrammes/model-of-care-for-the-provision-of-insulin-pump-therapy-tochildren-under-the-age-of-5.pdf.

40. Zinman B, Tildesley H, Chiasson JL, Tsui E, Strack T. Insulin lispro in CSII Results of a double-blind crossover study. Diabetes. 1997;46(3):440-3. https://doi.org/10.2337/diabetes.46.3.440.

41. Office CS. Census 2016. Summary results - part 1. Central Statistics Office, Ireland; 2016. [cited 2016 Cited Cited]. Available from: https://www.cso.ie/ en/media/csoie/newsevents/documents/census2016summaryresultspart1/ Census2016SummaryPart1.pdf.

42. Anthony Staines et al. Towards the Development of a Resource Allocation Model for Primary, Continuing and Community Care in the Health Services. Dublin City University; 2010. [cited 2010 Cited Cited]. Available from: http:// doras.dcu.ie/15131/1/ram-volume2-technical-report.pdf.

43. Wong JC, Boyle C, DiMeglio LA, Mastrandrea LD, Abel KL, Cengiz E, et al. Evaluation of pump discontinuation and associated factors in the T1D exchange clinic registry. J Diabetes Sci Technol. 2017;11(2):224-32. https:// doi.org/10.1177/1932296816663963.

\section{Publisher's Note}

Springer Nature remains neutral with regard to jurisdictional claims in published maps and institutional affiliations.

Ready to submit your research? Choose BMC and benefit from

- fast, convenient online submission

- thorough peer review by experienced researchers in your field

- rapid publication on acceptance

- support for research data, including large and complex data types

- gold Open Access which fosters wider collaboration and increased citations

- maximum visibility for your research: over $100 \mathrm{M}$ website views per year

At BMC, research is always in progress.

Learn more biomedcentral.com/submission 